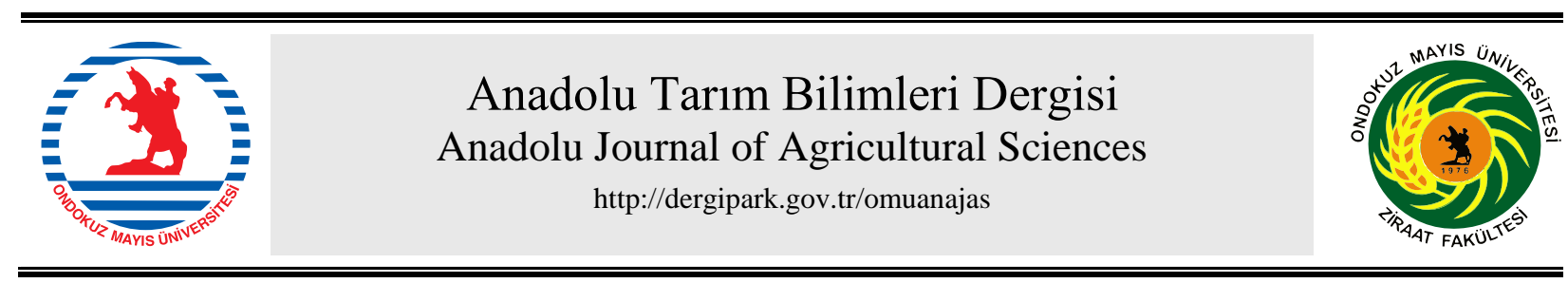

Araştırma/Research

Anadolu Tarım Bilim. Derg./Anadolu J Agr Sci, 35 (2020)

ISSN: 1308-8750 (Print) 1308-8769 (Online)

doi: 10.7161/omuanajas.645930

\title{
Terme Ovasında çeltik yetiştirilen alanların tuzluluk ve sodyumluluk durumlarının belirlenmesi
}

\author{
○Kübra Taşdelen ${ }^{\mathrm{a}^{*}}$, ○Yusuf Demir ${ }^{\mathrm{b}}$ \\ ${ }^{a}$ Ondokuz Mayıs Üniversitesi, Ziraat Fakültesi, Tarımsal Yapılar ve Sulama Bölümü, Samsun, Turkey \\ *Sorumlu yazar/corresponding author: tasdelenkubra77@gmail.com
}

Geliş/Received 12/11/2019 Kabul/Accepted 17/02/2020

\begin{abstract}
ÖZET
$\mathrm{Bu}$ çalışma Samsun İli Terme ovasında çeltik tarımı yapılan alanların toprak özelliklerinin belirlenerek bu alanların tuzluluk ve sodyumluluk durumlarının tespitini yapmak amacıyla gerçekleştirilmiştir. Çalışma alanından 2018 yılında 60 farklı noktadan, 0-30 cm, 30-60 cm, 60-90 cm ve 90-120 cm olmak üzere 4 farklı derinlikten toplamda 240 adet toprak örneği alınmıştır. Toprakların tekstür, elektriksel iletkenlik (EC), toprak reaksiyonu $(\mathrm{pH})$ ve değişebilir sodyum yüzdesi (ESP) içerikleri laboratuvar analizleri ile belirlenmiştir. Bazı toprak özelliklerine ait bazı tanımlayıcı istatistik analizi yapılmış ve Coğrafi Bilgi Sistemleri (CBS) kullanılarak toprakların EC ve ESP'sinin alansal dağılım haritaları oluşturulmuştur. Çalışma alanı topraklarının elektriksel iletkenlik (EC) değerleri $0.12 \mathrm{dS} / \mathrm{m}$ ile 2.92 $\mathrm{dS} / \mathrm{m}$ arasında değişmekte, genel olarak tuzsuz veya hafif tuzlu olmaktadır. Çalışma alanı topraklarının ESP değerleri ise \%1.15 ile \%12 arasında değişim göstermiştir. Deneme arazisinin bazı kısımlarında "sodyumlu" toprakların mevcut olduğu saptanmıştır. Alanın büyük çoğunluğunda ise ESP değerlerinin \%6'dan düşük, yani sodyum bakımından sorunsuz olduğu belirlenmiştir.
\end{abstract}

Determination of salinity and sodicity conditions of rice growing areas with geographical information systems in Terme Plain

\section{ABSTRACT}

This study was carried out in order to determine the soil characteristics of paddy cultivation areas in Terme plain and to determine the salinity and sodium status of these areas. The study was conducted in 2018 in the post-irrigation period. In the study, 240 soil samples were collected from 4 different depths of $0-30 \mathrm{~cm}, 30-60 \mathrm{~cm}, 60-90 \mathrm{~cm}$ and $90-120 \mathrm{~cm}$ at 60 different points representing the study area in the post harvest period. Physical and chemical analyzes of the samples were performed. Descriptive statistical analysis of the obtained data was made and spatial distribution maps of the area were created by using Geographical Information Systems (GIS). It was observed that the electrical conductivity (EC) values of the study area soils ranged from $0.12 \mathrm{dS} / \mathrm{m}$ to $2.92 \mathrm{dS} / \mathrm{m}$. The soil of the study area was determined to be salty or slightly salty. In general, it was determined that there is no salinity problem in the study area soils. Exhengeable sodium percentage was ranged from 1.15\% to $12 \%$ in the study area soils. It was observed that "sodic" soils in the study area. The ESP value was found to be less than $6 \%$ in the majority of the area.
Anahtar Sözcükler: Değişebilir sodyum Toprak tuzluluğu Coğrafi bilgi sistemi
Keywords:

Exchangeable sodium Soil salinity GIS 


\section{Giriş}

Toplumumuzda su kullanımı artış göstermektedir. $\mathrm{Su}$ kaynaklarının kullanımındaki artış, tarla içi sulamalarda önemli sorunlara neden olabilmektedir (Ghassemi ve ark., 1995). Toprakta sulama ve drenaj ilişkileri bağlantılı olarak bir düzen içerisinde olması gerekir. Bu ilişkinin sağlanamadığı durumlarda su-hava dengesi hava aleyhine bozulmaktadır. Bunun sonucu olarak verimin azalmasina neden olan tuzluluk ve sodyumluluk sorunları ortaya çıkmaktadır (Cemek ve ark., 2006). Toprakta tuzluluk ve sodyumluluk sorununun ortaya çıkması sonucunda kültür bitkilerinin çimlenme, büyüme ve ürün verimleri, mevcut tuzların ve sodikliğin cinsi ve miktarlarına bağlı olarak azalmakta ve hatta bazen tamamen durmaktadır (Richards, 1954; Dizdar, 1978). Coşkun (2016) yapmış olduğu çalışmada yağışlı dönem fazlalığının, killi ağır bünyeli topraklarda drenaj sorunu oluşturduğunu ve bu durumun toprakta tuzluluk gibi sorunlar çıkardığını belirtmiştir.

Kültür bitkilerinden bol ve kaliteli ürün alınabilmesi, yetiştirme ortamında bulunan bitki besin maddelerinin uygun miktarda ve yeteri miktarda bulunmasiyla yakından ilgilidir. Bitki besin maddelerinden herhangi birinin yetişme ortamında fazla ya da noksan bulunması bitki gelişimini ve bitkilerin toprakta bulunan besin maddelerinden yeterince yararlanmaların sınırlandırmaktadır. Tarımsal üretimle ilgili ortaya çıkan problemlerin çözülmesi için toprakta fiziksel ve kimyasal özelliklerin doğru bir şekilde belirlenmesi oldukça önemlidir (Taban ve ark., 1997). Toprak tekstürü, tarla kapasitesi (TK), solma noktası (SN); elektrik iletkenlik (EC), toprak reaksiyonu ( $\mathrm{pH}), \mathrm{Na}, \mathrm{K}$, $\mathrm{Ca}$ ve $\mathrm{Mg}$ değerleri vb. gibi toprak özelliklerinin belirlenerek aralarındaki ilişkilerin saptaması da oldukça önemlidir.

Çeltik tarımında tuzluluk ve sodyumluluk sorunları yaşanmaktadır. Bu sorun, ekim yapılan alandaki mevcut toprak özelliğinden, zaman zaman da sulama suyunun bu karakterleri göstermesinden dolayı oluşmaktadır. A.B.D. tuzluluk laboratuvarı ölçümlerine göre çeltik tuza hassas bitki sinıfina girmektedir. EC $4 \mathrm{dS} / \mathrm{m}$ tuz konsantrasyonunda çeltik veriminde $\% 50$ oranında düşme olmaktadır ( Richards, 1954). Çeltik yüksek sodikliğe toleranslıdır ve uygun kültürel tedbirler uygulandığında yeterli verim verir. ESP \%50 de çeltik verimi etkilenmemektedir. Çeltik yüksek ESP'ye toleranslıdır, çünkü su içinde yetiştirilir ve infiltrasyon ile toksik fazlalıklar uzaklaşır. Çeltik yüzeysel kök sistemine sahiptir ve bu yüzden toprağın üst katmanından, çok az derinlikte bir kısmında sodikliğin azaltılması ile ürün iyi bir şekilde yetiştirilebilir (Abrol ve ark., 1985). Değişebilir sodyum ile $\mathrm{pH}$ arasında bir ilişki mevcuttur. Değişebilir sodyum yükselmesi toprak pH'sını etkiler ve pH'nın yükselmesine neden olur. Toprak pH'sının yüksek olması bitki üzerinde doğrudan olumsuz etki oluşturmaz. Ancak bazı temel bitki besin maddelerinin mevcut durumunu azaltır. Sodik toprak, toprak kolloidleri üzerinde fazla miktarda değişebilir $\mathrm{Na}+$ içerir ve daha yüksek toprak pH'sına neden olan çözünür karbonatlara sahiptir (Batarseh, 2017). Yapılan bir araştırmada ESP deki yükselme toprak solüsyonun da $\mathrm{pH}, \mathrm{Na}^{+}, \mathrm{K}^{+}$yükseltip, $\mathrm{Ca}^{+2}$ ve $\mathrm{Mg}^{+2}$ düşürdüğü görülmüştür. Bitkilerdeki $\mathrm{Na}$ yükselmesi ve Ca'un azalmasını toprak solüsyonunda ki Na konsantrasyonu ile ilişskili olduğu belirtilmiş̧ir (Bajwa, 1987).

Türkiye'nin bütün bölgelerinde yetiştirilmekte olan çeltik, tahillar içerisinde önemli bir yere sahip sıcak iklim bitkisidir. Dünya'da ekim alanı yönünden buğdaydan, üretimde ise mısırdan sonra ikinci sırada gelmekte olup, dünya nüfusunun yarısından fazlasının temel besinidir. TÜİK tarafindan yayınlanan verilerde Türkiye genelinde çeltik hasat edilen alanın 118100 ha ekim alanından üretilen çeltik ise 940 bin ton, ayrıca dekar başına alınan ortalama verimin de 706 kilogram olduğu bildirilmiştir (TÜIK, 2018). Çeltik üretimi en fazla Edirne'de gerçekleşirken, ikinci sırayı Samsun almıştır. Edirne 'de 398 bin ton gerçekleşen üretim, Samsun'da 133 bin ton olarak gerçekleşmiştir (TÜIK, 2018). Samsun ilinde çeltik ekim alanı ve üretimi bakımından Terme Ovası üçüncü sıradadır. Terme Ovası'nda 9 bin ton çeltik üretimi gerçekleşmekte, 679 $\mathrm{kg} / \mathrm{da}$ verim elde edilmektedir.

Tarım topraklarının oluşumu binlerce yıl sürmekte ve üretilemeyen, yenilenmesi nerdeyse imkansız olan bir kaynak olarak gösterilmektedir. Tarım topraklarının, ülkelerin gelişim göstermesi ve hayat standartlarının yükseltilmesi için sürdürülebilir planlamalar yapılarak, yönetilmesi ve kullanıma sunulması gerekmektedir. Tarım topraklarının sürdürülebilirliği için, toprak kaynaklarının incelenmesi, toprak özelliklerinin tespit edilmesi ve düzenli izleme-değerlendirme yapılması gerekmektedir (Özyazıcı ve ark., 2015). Toprak özelliklerinin belirlenerek ortaya konulmasında dört ana amaç mevcuttur. Bu amaçlar, 1) toprakları doğru bir şekilde sınıflandırarak toprak özelliklerine ait verileri ortaya koymak, 2) toprak oluşum süreçlerini daha iyi anlamak, 3) toprak etüdünün yararlılığını artırarak verilerin hazırlanmasına yardımcı olmak, 4) toprak özelliklerinin haritalandırılmasına yardımcı olmak şeklinde sıralanmaktadır (Franzmeier, 1977).Tarımda gelişmelere paralel olarak bitki ekim alanlarının üretim ve verimlerinin belirlenmesinde, toprak özelliklerine ait haritaların hazırlanması, yüzeysel dağılım gösteren verilerinin elde edilmesi ve depolanmasında Coğrafi bilgi sistemleri (CBS) yaygın olarak kullanılmaktadır (Çetin ve Diker,2003).

Bu çalışmada, Samsun ilinin Terme Ovası'nda çeltik yetiştirilen tarım alanlarının bazı toprak özelliklerinin incelenmesi, tuzluluk ve sodyumluluk durumlarının Coğrafi Bilgi Sistem ile dağılım haritalarının oluşturulması ve değerlendirilmesi amaçlanmıştır. 


\section{Materyal ve Yöntem}

\subsection{Materyal}

Araştırma Orta Karadeniz Bölgesinde bulunan Samsun ili Terme Ovası'nda yürütülmüştür. Terme ilçesi Terme Çayı kenarında ve denizden $3 \mathrm{~km}$ içeride kurulmuş; yüzölçümü $583 \mathrm{~km}^{2}$, toplam arazi varlığı 548570 dekar olup, ekonomisinin temel kaynağ tarımdır. Toplam arazi varlığının 426310 dekarında tarımsal üretim yapılmaktadır (Coşkun ve Dengiz, 2016). Çalışma alanının büyüklüğü yaklaşık 12699 da'dır. Çalışma alanı, Akarsuların zamanla taşıdığı ve farklı depozitler üzerinde oluşmuş aluviyal topraklardan oluşmaktadır. İlçede bulunan Terme Çayı çalışma alanı içerisinde bulunmaktadır. Çalışma alanında iklim özellikleri olarak Karadeniz iklimi görülmektedir. Terme ilinin yıllık ortalama sicaklığ $14.9^{\circ} \mathrm{C}$ 'dur. Y1llık ortalama yağış miktarı ise $1175 \mathrm{~mm}$ 'dir. Terme Meteoroloji Müdürlüğü'nün verilerine göre, 2014-2018 yıllarında ortalama en düşük sıcaklık $8.2^{\circ} \mathrm{C}$ ile Aralık ve Şubat, ortalama en yüksek sicaklık ise $24.3^{\circ} \mathrm{C}$ ile Ağustos aylarında görülmüştür. Nispi nem değerleri 2014-2018 yıllarında \%68.7-91.7 arasında değişim göstermiştir (Anonim, 2018).

\subsection{Yöntem}

Çalışma 2018 yılı sulama sonrası dönemde yürütülmüştür ve 60 noktadan toprak örneği alınmasına karar verilmiştir. Terme ilçe tarım müdürlüğü tarafindan terme ovasında çeltik tarımı yapılan arazilerin bilgileri temin edilmiştir. 60 noktadan $0-30 \mathrm{~cm}, 30-60 \mathrm{~cm}, 60-90$ $\mathrm{cm}$ ve 90-120 cm derinliklerden olmak üzere 4 farklı derinlikten Auger Hole tipi burgu ile bozulmuş toprak örneği Blake ve Hartge (1986)'de gösterilen yönteme göre alınmıştır. Örnek alınan noktaların koordinatları GPS ile kaydedilmiştir. Toprak örneklerinin alındığ lokasyonlar Şekil 1'de gösterilmiştir.

Çalışma alanındaki toprakların fiziksel ve kimyasal özellikleri: Elektrik iletkenlik (EC), toprak reaksiyonu (pH), toprak tekstürü (\% kil, \% kum ve \% silt miktarlar1), tarla kapasitesi (TK), solma noktası (SN), $\mathrm{Na}, \mathrm{K}, \mathrm{Ca}$ ve $\mathrm{Mg}$ değerleri belirlenmiştir. Çalışma alanından alınan toprak örnekleri analizleri aşağıdaki yöntemlere göre yapılmıştır.

Elektriksel iletkenlik (EC): Toprakların elektriksel iletkenlik değerleri, 1:1 oranında hazırlanan toprak-su süspansiyonunda cam elektrotlu EC-metre aleti ile belirlenmiştir (Richards, 1954).

Toprak reaksiyonu (pH): Gee ve Bauder (1986) belirttiği esaslara göre 1:2.5 toprak-su süspansiyonunda cam elektrotlu pH-metre ile ölçülmüştür.

Tarla kapasitesi (TK): Toprak örnekleri seramik levhalar üzerinde halkalara yerleştirilmiştir. Suyla doygun hale getirilerek basınçlı membran aleti ile üzerine $1 / 3$ atm'lik basınç uygulaması işlemi ile belirlenmiştir (Richards, 1954).
Solma noktası (SN): Toprak örnekleri seramik levhalar üzerinde halkalara yerleştirilmiştir. Suyla doygun hale getirilerek basınçlı membran aleti ile üzerine 15 atm'lik basınç uygulaması ile belirlenmiştir (Richards, 1954).

Tekstür: Bouyoucos'un (1951) belirttiği esaslara göre hidrometre yöntemi kullanılarak belirlenmiştir.

Değişebilir katyonlar: Değişebilir $\mathrm{Na}, \mathrm{K}, \mathrm{Ca}$ ve $\mathrm{Mg}$ miktarları toprak örneklerin 1.0 N Amonyum Asetat $(\mathrm{pH}=7)$ ile ekstrakte edilerek bulunmuştur (Richards 1954).

Değişebilir Sodyum: Değişebilir sodyum (Na) miktarları fleymfotometrik yöntemle (Richards 1954), toprakta bulunan sodyum amonyum asetat çözeltisiyle ekstrakte edilerek çözeltiye geçen sodyumun alev fotometrede okunması yöntemi prensibiyle belirlenmiştir.

Değişebilir Potasyum: Değişebilir potasyum (K) miktarları fleymfotometrik yöntemle (Richards 1954), toprakta bulunan potasyumun amonyum asetat çözeltisiyle ekstrakte edilerek çözeltiye geçen potasyumun alev fotometrede okunması yöntemi prensibiyle belirlenmiştir.

Değişebilir Ca ve Mg: Richards’ın (1954) belirttiği esaslara göre, EDTA ile titrimetrik yöntemle belirlenmiştir.

Çalışma alanı topraklarının EC, ESP, pH ve tekstür değerlerine ait en küçük, en büyük, ortalama, standart sapma ve varyasyon katsayısı değerleri hesaplanmıştır. Elde edilen EC ve ESP değerlerinin çalışma alanında alansal dağılımlarına ait haritalar hazırlanmıştır. Çalışma alanına ait potansiyel verim haritaları oluşturulmuştur. Çalışma alanına ait dağılım haritaları elde edilmesinde Coğrafi Bilgi Sistemlerinden (CBS) yararlanılmıştır. Verilerin Coğrafi Bilgi Sistemleri ortamında analiz edilebilmesi ve değerlendirilebilmesi için "ArcGIS 10.0" bilgisayar programı kullanılmıştır. Toprak özelliklerinin haritalanması ve yorumlanması çalışmalarında Inverse Distance Weight (IDW) enterpolasyon yöntemi kullanılarak bütün derinlik sınıflarına ait veri katmanları üretilmiştir.

2003 MS Excel programından yararlanılarak $\mathrm{Na}, \mathrm{K}$, $\mathrm{Ca}$ ve $\mathrm{Mg}$ değerleri meq/100 g olarak hesaplanarak Eşitlik 1 kullanılarak toprak örneklerinin değişebilir sodyum yüzdesi (ESP) değerleri hesaplanmıştır (Richards, 1954).

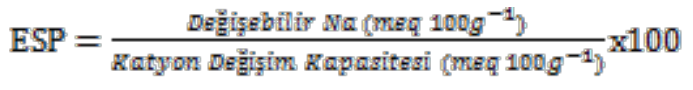

$\mathrm{Bu}$ çalışma kapsamında misır, soğan, fasulye ve çilek bitkileri için alandaki potansiyel verim haritaları hazırlanmıştır. Bitkilerin potansiyel verimleri hesaplanırken Eşitlik 2 kullanılmıştır (FAO, 1976).

$$
Y r=100-b\left(E C_{e}-a\right)
$$


Eşitlikte;

$Y_{r}=$ Oransal bitki verimi (\%)

$E C e=$ Çamur süzüğ̈̈, tuz konsantrasyonu $(\mathrm{dS} / \mathrm{m})$

\author{
$a_{=}=$Tuzluluk eşik değeri (Verimin \%100'den \\ düşmeye başladığı $\mathrm{EC}$ değeri) \\ $b=$ Birim tuzluluk artışına karşılık verim kaybı
}

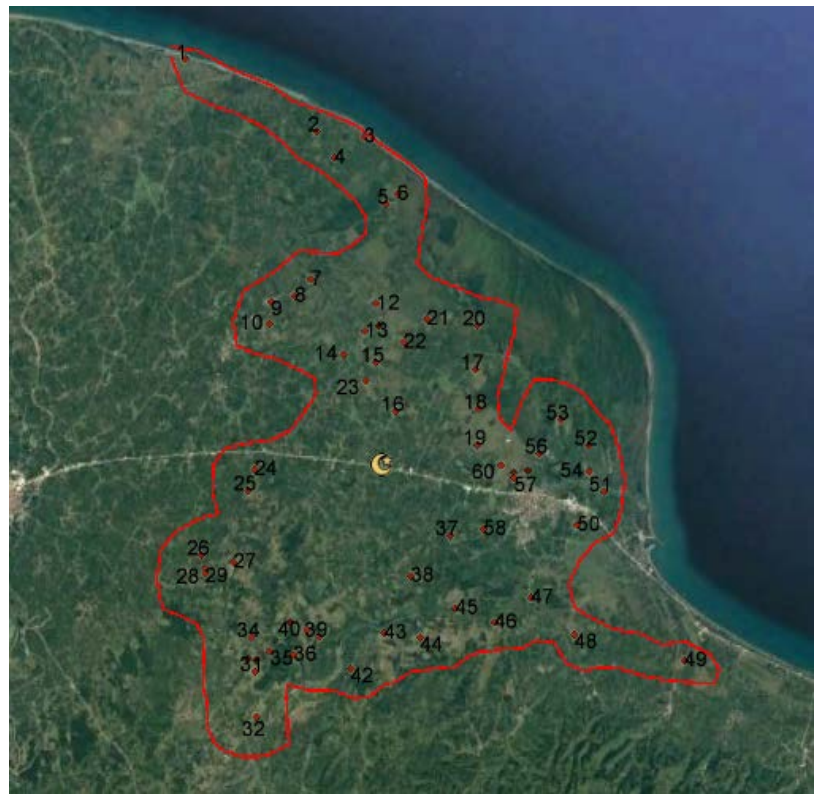

Şekil 1. Çalışma alanı örnekleme noktaları

Figure 1. Workspace sampling points

\section{Bulgular ve Tartışma}

\subsection{Araştırma topraklarının bazı fiziksel ve kimyasal özellikleri}

Çalıșma alanından 2018 y1lı sulama sonrası dönemde alınan toprakların tekstür özelliklerine ait en küçük, en büyük, ortalama, standart sapma ve varyasyon katsayısı değerleri Çizelge 1'de, EC, pH ve ESP değerleri tanımlayıcı istatistik sonuçları ise Çizelge 2'de verilmiştir. Toprakların kum içeriği ortalama \% 21.95 ile \% 29.27arasında, silt içeriği ortalama \% 22.45ile \% 24.13arasında ve kil içeriği ortalama \% 46.59 ile \% 55.60 arasında değişmiştir (Çizelge 1). Çalışma alanı topraklarının kum ve silt içeriği derinlikle birlikte artış gösterirken, kil içeriği derinlikle birlikte azalmıştır. Çalışma alanı topraklarının EC değerlerinin ortalaması 0.86 ile $1.38 \mathrm{dS} \mathrm{m}^{-1}$ arasında, $\mathrm{pH}$ değerlerinin ortalamas1 6.96 ile 7.26 arasında ve ESP değerlerinin ortalaması \% 3.37 ile \% 3.85 arasında değişmiştir (Çizelge 2).

Çalışma alanı topraklarının EC ve ESP değerleri derinlikle birlikte azalma gösterirken, $\mathrm{pH}$ derinlikle birlikte artmıştır. pH en küçük 4.62, en büyük 8.54 'tür. Toprak reaksiyonunun artma eğiliminde olduğu bölgeler denize yakın yerde ve deniz suyunun etkisiyle taban suyundaki dalgalanmalardan kaynaklanabilmektedir. Coşkun (2016) yapmış olduğu çalışmada Terme çayın ovaya girdiği yerden denize doğru olan doğrultuda toprak reaksiyonunun artma eğiliminde olduğu sonucuna varmıştır. En yüksek $\mathrm{pH}$ değerini denize en yakın yerde dağılım gösteren Çangallar serisinin yer aldığı topraklarda belirlemiştir.

Varyasyon katsayısı (VK), toprak özelliklerinin değişkenliğini tanımlamak için diğer parametrelere göre en ayırt edici faktördür (Zhang ve ark., 2007). Wilding (1985) ve Mulla ve Mc Bratney (2000) toprak özelliklerindeki değişimlerin açıklanmasında önemli bir gösterge olarak kabul edilen varyasyon katsayısını, aldığı değerlere göre \%15'ten küçük olanlar az değişken, \%15-35 arasında olanlar orta derecede değişken ve $\% 35$ 'ten büyük olanları yüksek derecede değişken olarak sınıflandırmaktadırlar. Çalışma alanı topraklarının kum ve silt içeriği tüm derinliklerde yüksek değişkenlik gösterirken, kil içeriği ise $0-30 \mathrm{~cm}$ ve $30-60 \mathrm{~cm}$ derinliklerde orta derece, $60-90 \mathrm{~cm}$ ve $90-$ $120 \mathrm{~cm}$ derinliklerde yüksek değişkenlik göstermiştir. Tekstürün yüksek derecede değişkenlik göstermesi alüvyal ana materyalin çalışma alanında farklılık göstermesi ve çalışma alanının geniş olmasına bağlanabilir. 
Çizelge 1. Çalışma alanı topraklarının bazı fiziksel özelliklerine ait bazı tanımlayıcı istatistikler

Table 1. Some descriptive statistics of some physical properties of the working area soils

\begin{tabular}{|c|c|c|c|c|c|c|}
\hline Toprak özellikleri & Derinlik(cm) & Min. & Max. & $\mathrm{AO}$ & S.S & VK \\
\hline \multirow{4}{*}{ Kum (\%) } & $0-30$ & 9.06 & 74.70 & 21.95 & 11.69 & 53.25 \\
\hline & $30-60$ & 8.17 & 92.92 & 24.10 & 15.26 & 63.34 \\
\hline & $60-90$ & 8.98 & 89.00 & 26.19 & 17.45 & 66.62 \\
\hline & $90-120$ & 9.37 & 92.99 & 29.27 & 21.66 & 73.99 \\
\hline \multirow{4}{*}{ Silt (\%) } & $0-30$ & 8.91 & 39.67 & 22.45 & 8.37 & 37.29 \\
\hline & $30-60$ & 1.80 & 45.36 & 22.82 & 8.22 & 36.04 \\
\hline & $60-90$ & 1.30 & 52.99 & 23.61 & 10.13 & 42.92 \\
\hline & $90-120$ & 1.30 & 49.10 & 24.13 & 11.75 & 48.69 \\
\hline \multirow{4}{*}{ Kil (\%) } & $0-30$ & 16.39 & 79.05 & 55.60 & 15.32 & 27.56 \\
\hline & $30-60$ & 5.28 & 78.42 & 53.08 & 16.39 & 30.88 \\
\hline & $60-90$ & 9.70 & 77.95 & 50.20 & 19.71 & 39.26 \\
\hline & $90-120$ & 5.57 & 78.75 & 46.59 & 19.68 & 42.23 \\
\hline
\end{tabular}

Min: Minimum değer, Max: Maksimum değer, AO: Aritmetik ortalama, S.S: Standart sapma, VK: Varyasyon katsayısı(\%)

Çizelge 2'den görüldüğü gibi EC ve ESP'nin varyasyon katsayısı yüksek bulunmuş ve yüksek düzeyde değişkenlik göstermiştir. $\mathrm{pH}$ değerlerine ait varyans katsayısı ise tüm derinliklerde en düşük olarak saptanmıştır. Böyle ki pH değerleri 0-30 cm ve 90-120 cm toprak katmanları az değişkenlik göstermiş, 30-60 $\mathrm{cm}$ ve $60-90 \mathrm{~cm}$ toprak katmanları orta derece değişkenlik göstermiştir.
Moasheri ve Foroughifar (2013) göre pH'nın düşük değişkenlik katsayısına sahip olması topraktaki ana madde bileşiminden kaynaklanmaktadır. Yüksek değișkenlik katsayısının ise gübreleme ve arazi kullanım tipi gibi arazi yönetim faktörlerinden kaynaklanabilir.

Çizelge 2. Çalışma alanı topraklarının bazı kimyasal özelliklerine ait bazı tanımlayıcı istatistikler

Table 2. Some descriptive statistics of some chemical properties of the working area soils

\begin{tabular}{lrrrrrr}
\hline Özellik & Derinlik $(\mathrm{cm})$ & Min. & Max. & AO & S.S & V.K \\
\hline \multirow{2}{*}{ EC $(\mathrm{dS} / \mathrm{m})$} & $0-30$ & 0.12 & 2.92 & 1.38 & 0.82 & 59.01 \\
& $30-60$ & 0.13 & 2.88 & 1.04 & 0.60 & 57.85 \\
& $60-90$ & 0.18 & 1.86 & 0.88 & 0.50 & 56.35 \\
& $90-120$ & 0.20 & 1.86 & 0.86 & 0.46 & 52.81 \\
\hline \multirow{2}{*}{$\mathrm{pH}$} & $0-30$ & 4.62 & 7.94 & 6.96 & 0.91 & 13.01 \\
& $30-60$ & 4.45 & 8.38 & 7.07 & 1.07 & 15.19 \\
& $60-90$ & 4.53 & 8.48 & 7.15 & 1.09 & 15.24 \\
& $90-120$ & 4.64 & 8.54 & 7.26 & 1.04 & 14.26 \\
\hline \multirow{2}{*}{ ESP (\%) } & $0-30$ & 1.15 & 10.30 & 3.85 & 2.03 & 52.88 \\
& $30-60$ & 1.27 & 10.91 & 3.55 & 1.96 & 55.23 \\
& $60-90$ & 1.23 & 12.00 & 3.54 & 2.04 & 57.77 \\
& $90-120$ & 1.25 & 10.37 & 3.37 & 1.90 & 56.45
\end{tabular}

Min: Minimum değer, Max: Maksimum değer, AO: Aritmetik ortalama, S.S: Standart sapma, VK: Varyasyon katsayısı(\%), EC:

Elektriksel iletkenlik, ESP: Değişebilir sodyum yüzdesi

\section{2. Çalışma alanı topraklarına ait EC ve ESP haritaların değerlendirmesi}

Richards, (1954) toprağın elektriksel iletkenlik değeri $2 \mathrm{dS} / \mathrm{m}$ ' den küçük olduğunda tuzsuz, 2-4 dS/m arasında olduğunda çok hafif tuzlu, 4-8 dS/m arasında olduğunda orta tuzlu, 8-16 dS/m arasında olduğunda çok tuzlu ve $16 \mathrm{dS} / \mathrm{m}$ ' den daha fazla olduğunda aşırı tuzlu olduğunu bildirmiștir. Şekil 2 incelendiğinde çalışma alanında alt katmanlara doğru tuzluluk değerlerinin azaldığı görülmüştür. Bunun sebebi derinlikle birlikte kil fraksiyonlarını azalması ve kum ile silt fraksiyonlarına bağlı olarak alt katmanlarda EC’yi yükseltecek kimyasal özelliklerin azalmasına ve ayrıca bu katmanlarda yıkama durumlarının daha yüksek olmasına bağlanabilir (Taşan, 2017). Tuzluluk değerinin en yüksek olduğu alanlar toprağın üst katmanında bulunmaktadır. Çalışma alanında $0-30 \mathrm{~cm}$ ve $30-60 \mathrm{~cm}$ katmanlarında hafif tuzlu alanlar tespit edilirken, $60-90 \mathrm{~cm}$ ve $90-120 \mathrm{~cm}$ katmanlarında 
tuzluluk değerinin $2 \mathrm{dS} / \mathrm{m}$ 'nin altında olduğu tespit edilmiştir. Toprak katmanları genel olarak incelendiğinde çalışma alanında tuzluluk probleminin olmadığı görülmüştür. Coşkun (2016) yapmış olduğu çalışmada terme çayı ve terme çayına yakın mevkilerde ki toprak özelliklerinin incelenmesi sonucu tuzluluk sorunu olmadığını bildirmiştir.

Şekil 3'te görüldüğ̈̈ gibi çalışma alanının büyük bölümünde ESP değeri 6'dan düşük yani sodyum bakımından sorunsuz olmaktadır. Çalışma alanının güney-batı bölümünde, toprakların 0-30 $\mathrm{cm}$ katmanında ESP değeri 6-14 arasında; alanın kuzey -batı bölümündeki toprakların $60-90 \mathrm{~cm}$ katmanında ise küçük bir alanda sodyumlu toprakların mevcut olduğu belirlenmiştir. Çalışma alanı toprak katmanları birlikte incelendiğinde alanın doğu bölümünde, Terme Çayı'nın
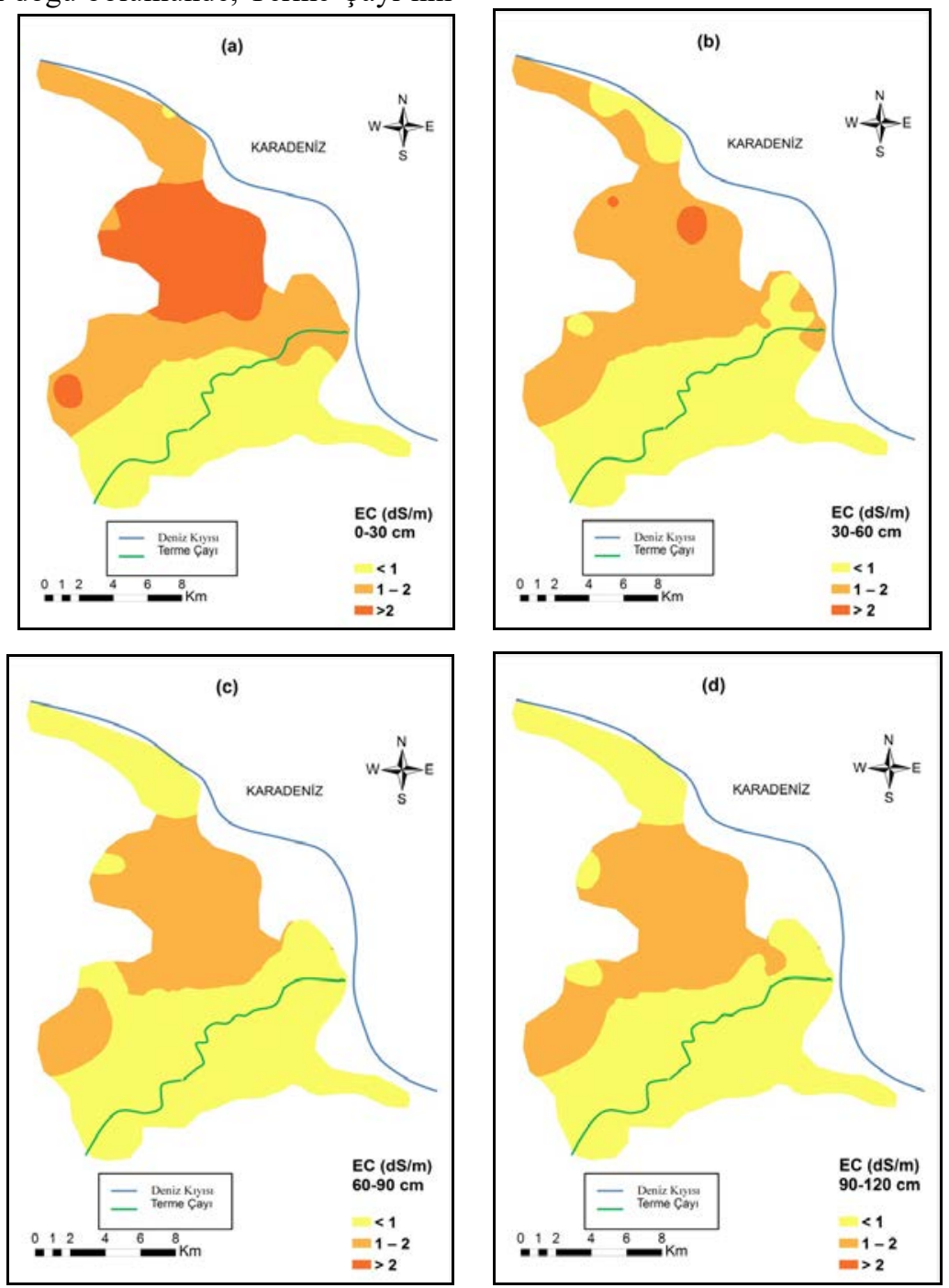

Şekil 2. Çalışma alanı topraklarının EC dağılım haritaları

Figure 2. EC distribution maps of working area soils 

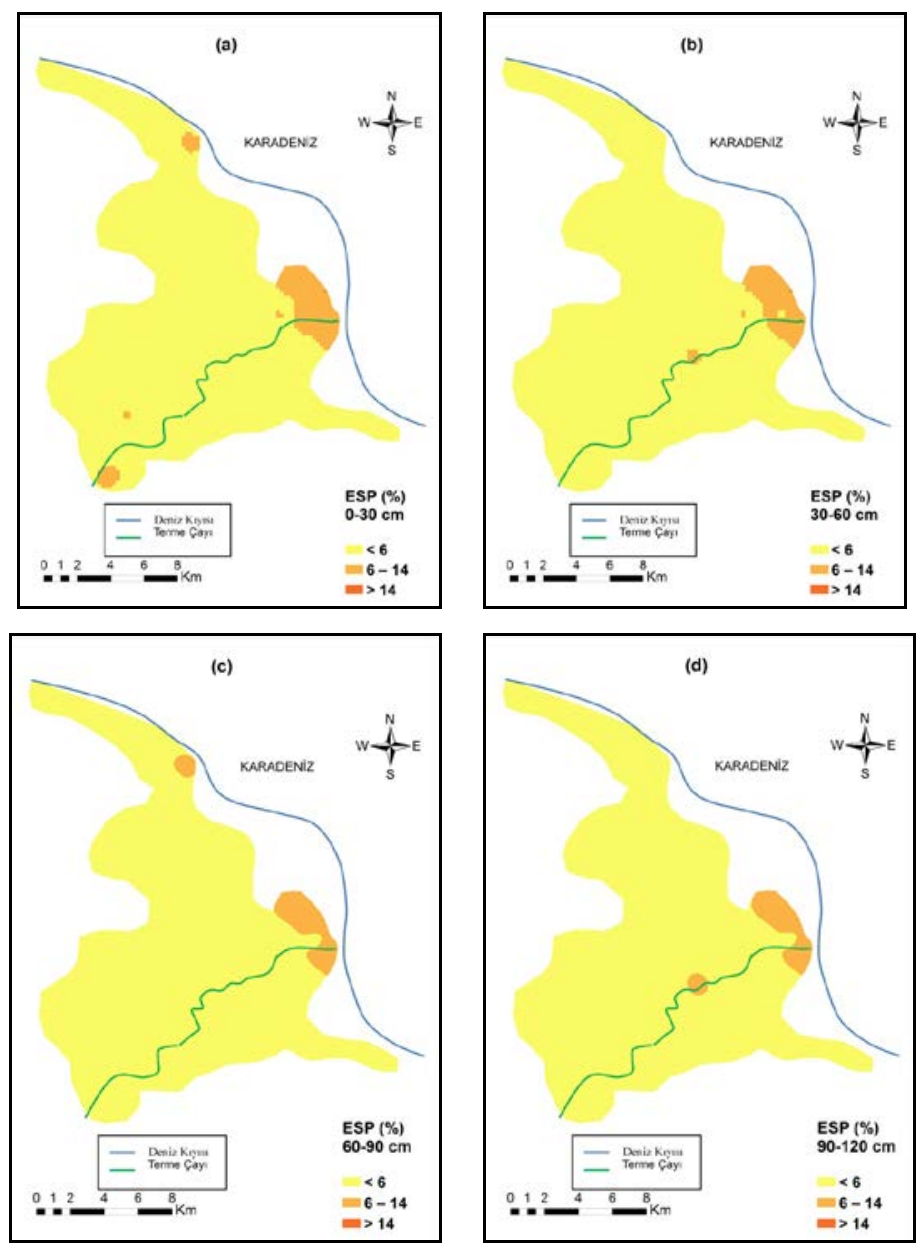

Şekil 3. Çalışma alanı topraklarının ESP dağılım haritaları Figure 3. ESP distribution maps of working area soils

\section{3. Çalışma alanına ait potansiyel verim haritaları}

Çizelge 3 'te yüzde $100,90,75,50$ ve 0 'lık potansiyel verimler için değerler verilmiştir. Toprak tuzluluğu ve verim potansiyeli arasındaki ilişkilerden (Çizelge 3) faydalanarak (FAO, 1976), çalışma alanının mevcut tuzluluk koşullarında mısır, soğan, fasulye ve çilek bitkileri yetiştirmek istendiğinde, potansiyel verimlerinin değişim oranları belirlenerek yapılan verim potansiyeli haritası Şekil 4 'te gösterilmiştir. Çalışma alanında mısır ekildiği durumda alanın çoğunluğunda herhangi bir verim kaybı olmadığı görülürken, yaklaşık $\% 11$ 'lik alanda \%0-10 arasinda verimde azalma görülmektedir. $\mathrm{Bu} \% 11^{\prime}$ lik alanda soğan bitkisi yetiştirilme koşulunda verimdeki azalma oranı \%1020'lere ulaşmaktadır. Soğan ekimi yapılma koşulunda alanın yaklaşı \%43'ünde verimde \%0-10'luk bir azalma görülmektedir. Alanın güney bölümünde ise verimde azalma mevcut değildir. Fasulye ekimi yapılma ihtimalinde alanın güney bölümünde $\% 45$ 'lik bir kesimde herhangi bir verim kaybı görülmezken, geriye kalan yaklaşık \%30'luk bir alanda \%10-20 arasında değişen oranlarda verimin azalacağı görülmektedir. Çilek bitkisi potansiyel verim haritası incelendiğinde ise çilek bitkisi ekimi yapılma ihtimalinde diğer bitkilere oranla daha yüksek verim kayıplarına rastlanabilmektedir. $\mathrm{Bu}$ verimde azalma oranı \%40'lara kadar ulaşabilmektedir. Bunun sebebi verimde \% 40'a düşen alanların tuzluluk değerinin çilek bitkisinde maksimum $\mathrm{EC}_{\mathrm{e}}$ sınırına yakın olmasından kaynaklanmaktadır. Öngörülen maksimum $\mathrm{EC}_{\mathrm{e}}$ veya yüzde 0 verim, çizelge 3'ün son sütununda verilmektedir. Genel olarak tüm bitkiler değerlendirildiğinde, çalışma alanının güney bölümünde tuzluluk açısından herhangi bir verim kaybı görülmemektedir (Şekil 4). Sulama sularıla tuzun toprağa iletilmesiyle tuz birikimi gerçekleşmektedir. Toprak çözeltisinde tuz birikimi gerçekleşerek üzerinde yetiştirilen bitkiler olumsuz olarak etkilenmekte ve verimde azalmalar oluşmaktadır (Kara ve Apan, 2000). Bütün bitkiler tuzluluğa benzer şekilde tepki vermez; bazı ürünler diğerlerine göre çok daha fazla toprak tuzluluğunda kabul edilebilir verim üretebilir. Bunun nedeni, bazı mahsullerin toprağından 
daha fazla su almasını sağlayan gerekli ozmotik ayarlamaları daha iyi yapabilmesidir. Toprak tuzluluğunun birikmesinin, yetiştirilecek ürün için kabul edilebilir bir konsantrasyonda kontrol edilemediği alanlarda, hem beklenen toprak tuzluluğuna daha toleranslı olan hem de ekonomik verim sağlayabilen alternatif bir mahsul seçilebilir (FAO, 1976).

Çizelge 3. Toprak tuzluluğu $\left(\mathrm{EC}_{\mathrm{e}}\right)$ ve verim potansiyeli arasındaki ilişkiler $(\mathrm{FAO}, 1976)$

Table 3. Relationships between soil salinity (ECe) and yield potential (FAO, 1976)

\begin{tabular}{|c|c|c|c|c|c|c|c|}
\hline \multirow[b]{2}{*}{ BİTKİLER } & Yüzdeverim & $\% 100$ & $\% 90$ & $\% 75$ & $\% 50$ & $\% 0$ & \\
\hline & & $\mathrm{EC}_{\mathrm{e}}$ & $\mathrm{EC}_{\mathrm{e}}$ & $\mathrm{EC}_{\mathrm{e}}$ & $\mathrm{EC}_{\mathrm{e}}$ & $\mathrm{EC}_{\mathrm{e}}$ & $\begin{array}{r}\text { Alanın } \\
\text { ortalama } \\
\text { verimi }\end{array}$ \\
\hline Misır & & 1.8 & 3.2 & 5.2 & 8.6 & 15 & $\% 100$ \\
\hline Soğan & & 1.2 & 1.8 & 2.8 & 4.3 & 7.4 & $\% 97$ \\
\hline Fasulye & & 1.0 & 1.5 & 2.3 & 3.6 & 6.3 & $\% 95$ \\
\hline Çilek & & 1.0 & 1.3 & 1.8 & 2.5 & 4.0 & $\% 91$ \\
\hline
\end{tabular}
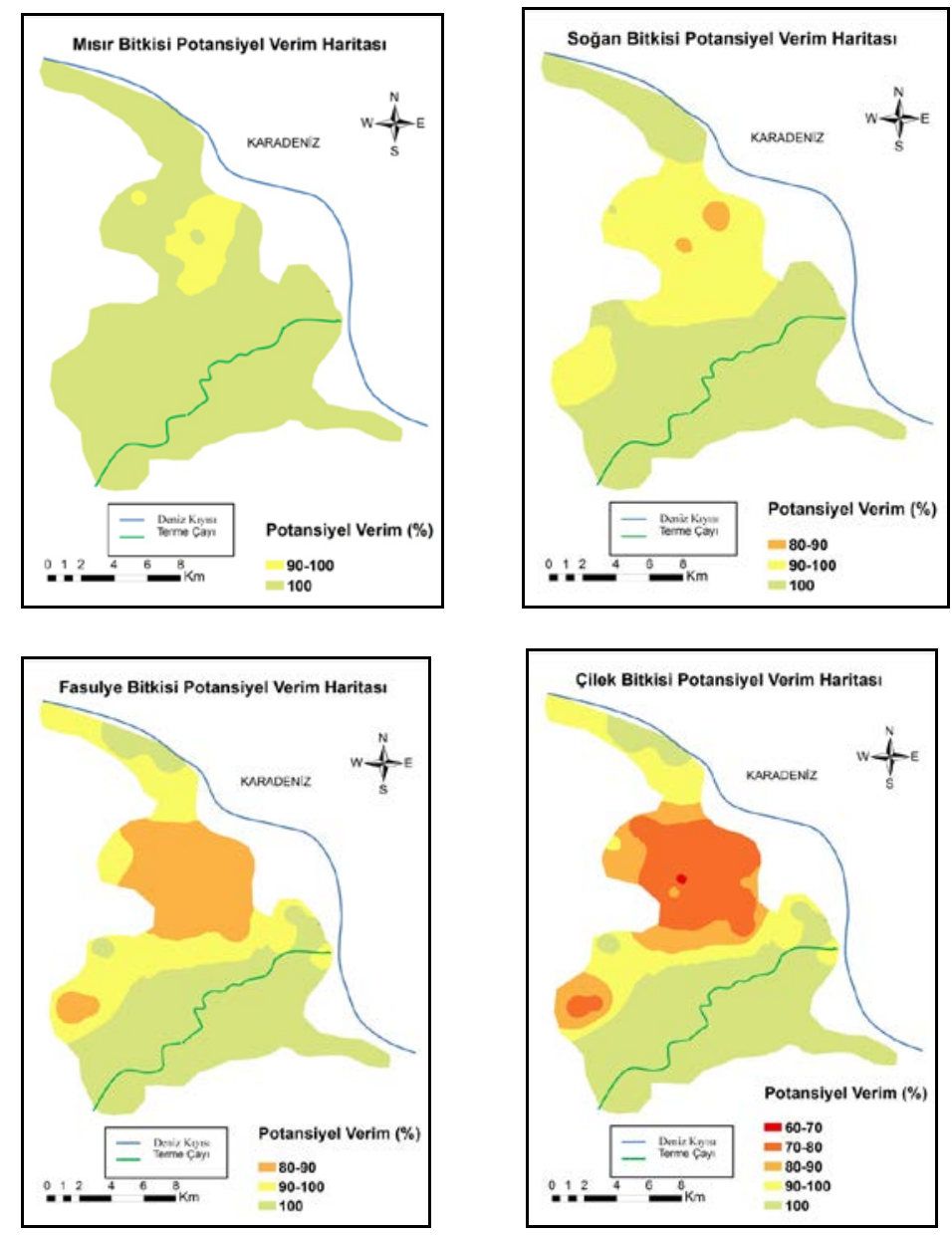

Şekil 4. Çalışma alanında mısır, soğan, fasulye ve çilek bitkilerine ait potansiyel verimlilik haritaları

Figure 4. Potential productivity maps of corn, onion, bean and strawberry plants in the study area 


\section{Sonuç ve Öneriler}

Toprakların kalitesinin ve karakteristik özelliklerinin zamanında belirlenmesi, özelliklerine göre kullanımları ve yönetilmesi önemlidir. $\mathrm{Bu}$ adımların zamanında atılmaması durumunda toprakların fiziksel, kimyasal ve biyolojik durumlarına yönelik sorunlar oluşmaktadır. Örnek olarak, organik madde yetersizliği, tuzluluksodiklik gibi nedenlerden kaynaklı toprakların fonksiyon gösterme yeteneğinin azalması ve zamanla arazilerin biyolojik üretkenliğini geri dönüşümsüz olarak kaybetmesi söylenebilir. En iyi toprak-bitki ve arazi yönetimlerinin seçimiyle tarımda sürdürülebilirlik sağlanabilir. Bunun için; toprak, iklim, bitki örtüsü ve arazi kullanımı gibi temel bilgilerin yer alacağ ${ }_{1}$ detaylı toprak etüd ve haritalama çalışmalarına ve süreç içerisinde izleme, değerlendirme ve güncellemeye imkan veren bir toprak veri tabanına ihtiyaç duyulmaktadır. Samsun ili Terme Ovası'nda çeltik yetiştirilen alanlardaki toprakların fiziksel ve kimyasal özellikleri incelenmiş, tarım alanlarının tuzluluk ve sodyumluluk yönünden elverişliliğ̣i araştırılmıştır. Araştırma sonuçlarına ArcGIS 10.0 Coğrafi Bilgi Sisteminden yararlanarak EC, ESP ve potansiyel verim haritaları oluşturulmuş ve değerlendirmeleri yapılmıştır. Terme Ovası çeltik alanlarında mevcut toprakların EC ve ESP değerleri tüm derinliklerde yüksek değişkenlik göstermiştir. $\mathrm{pH}$ çalışma alanında en düşük değişkenlik gösteren özellik olmuştur. Toprakların kum ve silt içeriği tüm derinliklerde yüksek değişkenlik gösterirken, kil içeriği ise $0-30 \mathrm{~cm}$ ve $30-60 \mathrm{~cm}$ derinliklerde orta derece, $60-90 \mathrm{~cm}$ ve $90-120 \mathrm{~cm}$ derinliklerde yüksek değişkenlik göstermiştir. Tekstürün yüksek derecede değişkenlik göstermesi alüvyal ana materyalin çalışma alanında farklılık göstermesi ve çalışma alanının geniş olmasına bağlanmıştır. Çalışma alanı, topraklarının tuzluluk (EC) değerleri incelendiğinde $0.12 \mathrm{dS} / \mathrm{m}$ ile $2.92 \mathrm{dS} / \mathrm{m}$ arasında değiştiği görülmüştür. Çalışma alanı topraklarının tuzsuz veya hafif tuzlu olduğu belirlenmiştir. Tuzluluk değerinin en yüksek olduğu alanlar toprağın üst katmanlarıdır. Toprağın alt katmanlarına doğru EC değeri azalma göstermektedir. $\mathrm{Bu}$ durum derinlikle birlikte kil içeriğinin azalması ve kum ile silt içeriklerine bağlı olarak alt katmanlarda EC'yi yükseltecek kimyasal özelliklerin azalmasına ve ayrica bu katmanlarda yıkama durumlarının daha yüksek olmasına bağlanmıştır. Ergene (1987), kil ve organik maddece zengin toprakların toprakta tutulan su miktarlarını arttırdığını belirtmektedir. Genel olarak çalışma alanı toprakları değerlendirildiğinde tuzluluk sorunu bulunmadığı belirlenmiştir. Çalışma alanı topraklarının ESP değerleri incelendiğinde ise ESP değerinin \%1.15 ile \%12 arasında değiştiği görülmüștür. Çalışma alanının genel olarak sodyum bakımdan sorunsuz olduğu tespit edilmiş ancak terme çayının denize döküldüğü alanda sodyumlu toprakların mevcut olduğu belirlenmiştir. Bu durum, bu kısımlarda taban suyu seviyesinin yüksek olmasına ve sulama suyunda kötü kaliteli su kullanılmasına bağlanabilir. Çalışma alanının mevcut tuzluluk koşullarında mısır, soğan, fasulye ve çilek bitkilerinin potansiyel verimlerinin değişim oranları incelenmiştir. Bu bitkiler ekim için tercih edildiğinde, misır $\% 100$, soğan $\% 97$, fasulye \%95 ve çilek \%91 oranda verim gösterecektir. Ovanın genelinde, çeltik üretimi yapılan alanlarında tuzluluk ve sodyumluluk yönünden önemli bir sorun tespit edilmemiştir. Ancak tuzlu ve sodyumlu toprakların artış gösterdiği alanlarda bu artışın kontrolü için izleme ve değerlendirmeler devam ettirilmelidir. Ayrıca tarım arazilerinde kullanılan su ve sulama sularındaki parametreler önemlidir. Bölgede bundan sonra yapılacak çalışmalarda su kaynaklarının da değerlendirmelere katılması yararlı olacaktır. Bitkilerin tuz toleranslarının farklılıkları bakımından, bitkilerde verim ve kalite açısından önemli değișiklikler oluşmaktadır. $\mathrm{Bu}$ nedenle tuz ve sodyumluluk problemlerini yaşamaya başladığı alanlarda tuza dayanıklı bitkilerin seçilmesi önerilmektedir. $\mathrm{Bu}$ çalışmanın yapıldığı Samsun İli Terme Ovasında da tuzluluk ve sodyumluluk problemlerinin yaşanması ihtimaline karşılık problemli alanlarda tuza toleranslı bitkiler yetiştirilmelidir.

\section{Teșekkür}

$\mathrm{Bu}$ çalışma Ondokuz Mayıs Üniversitesi BAP Koordinatörlüğü tarafindan 1904.17.042 numaralı proje ile desteklenmiştir.

\section{Kaynaklar}

Abrol, I.P., Bhumbla, D.R., Meelu, O.P., 1985. Influence of salinity and alkalinity on properties and management of rice lands. pp. 183-198. In: Soil Physics and Rice. E.A. Tout and G.S. Argosina. Int. Rice Res. Inst., Los Banos, The Philippines.

Anonim, 2018. Samsun ili Terme ilçesi iklim verileri. Meteoroloji İşleri Genel Müdürlüğü, MEVBİS, Samsun.

Anonim, 2019. Toprağın katı ve sıvı fazı arasındaki etkileşimler.

URL: https://obs.ahievran.edu.tr/oibs/akademik/shr_f iles/FILE_8zt53fbdrhp111zchsmrfkg3legxu_d uyuru.PDF. (Erişim tarihi: 05.04.2019).

Batarseh, M., 2017. Sustainable Management of Calcareous Saline-Sodic Soil in Arid Environments: The Leaching Process in the Jordan Valley. Applied and Environmental Soil Science, Volume 2017, Article ID 1092838:19.

Blake, G. R., Hartge, K., 1986. Bulk Density1. Methods of Soil Analysis: Part 1- Physical and Mineralogical Methods. pp. 363-375.

Bouyoucos, G. J. 1951. A recalibration of the hydrometer method for making mechanical analysis of the soils. Agronomy Journal, 43(9): 343-348. 
Cemek, B., Güler, M. ve Arslan, H., 2006. Bafra ovas1 sağ sahil sulama alanındaki tuzluluk dağılımının coğrafi bilgi sistemleri (CBS) kullanılarak belirlenmesi. Atatürk Üniversitesi Ziraat Fakültesi Dergisi, 37(1): 63-72.

Coşkun, A., 2016. Terme Havzası bazı temel Fizyografik karakteristikleri belirlenmesi ve tarımsal taşkın alanlarının toprak haritalanması. Ondokuz Mayıs Üniversitesi Fen Bilimleri Enstitüsü, Yüksek Lisans Tezi, 43.

Coşkun, A., Dengiz, O., 2016. Terme Havzası bazı temel Fizyografik karakteristikleri belirlenmesi ve tarımsal taşkın alanlarının toprak haritalanması. Türkiye Tarımsal Araştırma Dergisi. 3: 1-13.

Çetin M, Diker K., 2003. Assesing drainage problem areas by GIS: A case study in the eastern mediterranean region of Turkey. Irrigation and Drain. 52: 343-353.

Dizdar, M.Y., 1978. Türkiye'de tuzdan etkilenmiş topraklar. Toprak Su Dergisi, 47: 36-57.

Ergene A., 1987. Toprak Biliminin Esasları, Genişletilmiş 4. bask1 Atatürk Üniversitesi Yayın no: 635, Ziraat Fak. Yay.289. Ders Kitap Serisi 47. Atatürk Üniversitesi Basım evi, Erzurum.

FAO, 1976. Water Quality for Agriculture. Irrigation and Drainage Paper, No: 29, Rome.

Franzmeier, D. P., 1977. Soil Characterization in Indiana: Field and laboratory procedures. I:943 Purdue University Agricultural Experiment Station.

Gee, G. W. and Bauder J.W. 1986. Partical-Size Analysis. p. 383- 411. In A. Klute (ed.) Methods of Soil Analysis. Part 1. Physical and Mineralogical Methods. 2nd ed. Agron. Monogr. 9. ASA and SSSA, Madison, WI. USA.

Ghassemi, F.A., Jakeman, J., Nix, H.A., 1995. Salinisation of land and water resources. Centre for Resource and Environmental Studies. The Australian National University. Canberra. Australia.

Güler, M., Arslan, H., Cemek, B., Erşahin, S., 2014. Long-term changes in spatial variation of soil electrical conductivity and exchangeable sodium percentage in irrigated mesic ustifluvents. Agricultural Water Management, 135: 1-8.

Hazelton, P. and Murphy, B,. 2007. Interpreting soil test results: What do all the numbers mean? : NSW Department of Natural Resources.

Kara, T., Apan . M., 2000. Tuzlu taban suyunun sulamalarda kullanımı için bir hesaplama yöntemi. O.M.Ü. Ziraat Fakültesi Dergisi, 15(3):62-67.
Moasheri, S. A., Foroughifar, H., 2013. Estimation of the values of soil absorption ratio using integrated geostatistical and artificial neural network methods. International Journal of Agriculture and Crop Sciences (IJACS), 5(20): 2423-2433.

Mulla, D.J., Mc Bratney, A.B., 2000. Soil Spatial Variability. Handbook of Soil Science CRS Pres, pp: 321-352.

Northcote, K. H., Skene, J. K. M., 1972. Australian soils with saline and sodic properties. CSIRO Australia, Soil Publication No. 27, Canberra.

Özyazıc1, M. A., Dengiz, O., Aydoğan, M., Bayraklı, B., Kesim, E., Urla, Ö., Yıldı, H. ve Ünal, E., 2015. Orta ve Doğu Karadeniz Bölgesi tarım topraklarının temel verimlilik düzeyleri ve alansal dağılımları. Anadolu Tarım Bilimleri Dergisi, 31(1):136-148.

Rhoades, J., Chanduvi, F., 1999. Soil salinity assessment: Methods and interpretation of electrical conductivity measurements (Vol. 57): Food and Agriculture Org.

Richards, L., 1954. Diagnosis and improvement of saline and alkali soils. United States Salinity Laboratory. Agriculture Handbook No.60, USDA, Washington.

Singh, B., Bajwa, M.S., 1987. Efficiency of urea as affected by time and method of its application to rice grown in partially reclaimed sodic soils. Oryza, 24: 7-13.

Taban, S., Alpaslan, M., Hashemı, A. G., Eken, D., 1997. Orta Anadolu'da çeltik tarımı yapılan toprakların bazı fiziksel ve kimyasal özellikleri. Pamukkale Üniversitesi Mühendislik Bilim Dergisi, 3(3): 457-466.

Taşan, M., 2017. Samsun İli Alaçam İlçesi Kıyı Bölgesi Çeltik Alanlarının Sulanmasında Yeraltı Suyu Kullanımının Toprak-Su Özellikleri ve Deniz Suyu Girişimine Etkilerinin Farklı Enterpolasyon Yöntemleri ile Değerlendirilmesi. Ondokuz Mayıs Üniversitesi Fen Bilimleri Enstitüsü, Doktora Tezi, 267.

Wilding, L.P., 1985. Spatial Variability: It's documentation, accommodation and implication to soil surveys. In: Soil Spatial Variability, (Eds: Nielsen, D.R. and J. Bouma) Pudoc, Wageningen, The Netherlands, pp: 166194.

Yurtseven, E., Öztürk, A., Kadayıfçı, A. Ve Ayan, B., 1996. Sulama suyu tuzluluğunun Biberde (Capsium annuum) farklı gelişme dönemlerinde bazı verim parametrelerine etkisi. Tarım Bilimleri Dergisi, 2(2): 5-10.

Zhang, X.-Y., Yue-Yu, S., Zhang, X.-D., Kai, M., Herbert, S., 2007. Spatial variability of nutrient properties in black soil of northeast China. Pedosphere, 17(1):19-29. 